\title{
Public Perception of International Standardized Madras
}

\author{
Dr. Asep Saifuddin Chalim, MA \\ The State Institute for Islamic Studies (IAIN) Sunan Ampel, Surabaya, Indonesia.
}

\begin{abstract}
There has been a debate whether the International Standardized Boarding Schools have an ability to increase the level of education of the community. This paper describes and analyzes the perceptions of stakeholders towards the implementations of the International Standardized Boarding Senior High School (the ISBSHS) located in Pacet, East Java Province, Indonesia. The data is collected by interview, observation and documentations. We found that the perceptios of parents, stakeholders, students, alumni, education experts and community leaders on the quality of learning system of the school grow positively.Thus, it brings the confidence that academics, moral and religious goals of the school will be achieved.
\end{abstract}

Keywords: Boarding school, international standardized school, good school governance, perception

\section{Introduction}

As we know that in this era of globalization, competition in various fields of business which is no exception-in-education is increasing. Freedom of exit-entry as characteristic of globalization will open up the opportunity for every foreign educational institutions into the domestic market of every country. To increase competitiveness, many educational institutions in Indonesia have established international standardized schools. However, in reality the presences of international standardized schools are causing controversy in the society. The pros argue that the existence of international schools able to improve the quality of the graduates that can compete internationally. However, the cons argue that the cost of international standardized schools are very expensive, while the Indonesia people are generally poor. As a result, only rich people can afford to go to the international standardized schools. This is what will cause injustice in the society which will further inflame tensions and social conflicts, both physical and non-physical. In addition, they also argue that an international standardized schools do not necessarily have a sophisticated program that will produce superior or excellent quality graduates compare to the regular school graduates. Hence, they make efforts to ban the implementation of international standardized boarding senior high school through government and parliement.

In the midst of the controversy, in 2005, the Education Foundation of Amanatul Ummah (AU) held the International Standardized Boarding Senior High School (the ISBSHS) located in Pacet, East Java Province, Indonesia. Although located in remote rural areas, the school has grown rapidly as indicated by the number of students from 49 students in 2005 increased to approximately 800 students in 2012. This phenomenon is very interesting to investegate.This paper tries to answer what exactly the public perception of the International Standardized Boarding Senior High School, especially High School of Amanatul Ummah (the ISBSHS) located in Pacet, East Java Province, Indonesia?The aim of this study is to describe and analyze the perceptions of stakeholders towards the implementation of the ISBSHS located in Pacet, East Java Province, Indonesia.At the theoretical level, the results of this study are expected to enrich the vocabulary of social science theory about public perception related to educational models such as the ISBSHS. Based on the paradigm of social reality that developed during this research could provide a logical consequence for the birth of a new perspective on growing concept of sociology of education and the concept of social change.Moreover, at the practical level, it will be one of the considerations by the government or related agencies especially the Ministry of National Education of the Republic of Indonesia in making education policy, especially policies for the international standardized senior high school.

\section{Literature Review}

\section{Social Education Concepts}

Sociology of education is the study of the sociology of applied science in solving the fundamental problem of education. Even in the Dictionary of Sociology mentioned clearly that the sociology of education is more focused on how the sociologist looking and thinking and applying social science as a basis for departure to solve the problems that arise in the world of education. Furthermore, the conception of the sociology of education is the concept of management education policy implementation process to be more effective in accordance with the policy plan that has been outlined by the institution. According to Maliki (2008): 
"Sociology of education is useful to assist the analysis of planning, implementation and implications of the implementation of specific educational programs or policies"

The sociological policy gives emphasis to accomodate various inputs to all the problems that arise in the realities of educational institutions, which is delivered by every man who became the implementers of education, so that education policy is more systematic and focused as planned by the educational institution. This is in line with Ahmadi's argumentation (1991) which states that: "Sociology of education is an analysis of the sociological processes that take place in educational institutions".

Sociology of education also gives the concentration of efforts towards the achievement of macro strategy through the use of sociology as a basis for measuring and utilization of any changes in education policy. Thus, the sociology of education provides the fundamental value of the benefit to the creation of the impact of social change in educational institutions for the realization of the targets that have been outlined by the institution. Furthermore, Saha (2008) defines sociology of education as the study of educational structure, processes, and practices from a sociological perspective.Related to the research context, the concept of sociology of education is used as an explanatory concept considering research on the ISBSHS directly intersect with social studies related to aspects of education. In other words, the concept of educational sociology is useful in explaining the phenomenon of education that takes place in the ISBSHS, especially in sociological perspective.

Arifin (1998) suggested that the outstanding school has characteristics: (a) a good learning facility and exclusive, (b) good academic services, (c) good planning; (d) work climate and healthy learning; (e) achievement motivation and high morale; (f) high expectations and strong support from parents and the surrounding community; ( $\mathrm{g}$ ) the involvement of teachers, and (h) led by an effective principal. Factors that support the achievement include: (a) physical facilities and equipment (b) the teachers and support staff are competent and highly committed; (c) differentiated learning, (d) high expectations and beliefs, and strong support from parents and the surrounding community; (e) effective and harmonious organization; (f) commitment to the local culture and religion; (g) a healthy working environment, and the high motivation and morale; (h) high involvement of teachers; (i) an effective principal, and (j) a support of some creative people.

The outstanding school is a school that promotes quality, even applying the approach of the business management principles to support the school's academic program, unlike other education institutions which are generally more stressed merely to the equal education opportunities.

Sujarwo (2000) argued that humans are born to grow and develop through social interaction that they develop. Therefore, many sociologists say that the core of the social processes is laying on the social interaction. At the same time, it gradually started growing knowledge of the norm. The norms include social norms, family norms, and religious norms. The main subject of knowledge of norm is through social interaction. As a concrete example of the norm: someone can be considered successful in formal education if he or she passing the exam at a certain level. This norm leads a person at a particular level in the educational process. Meanwhile, the components of norms in the teaching are: (a) the intensity of the teacher giving a lesson, (b) a method of teaching applied by teachers, and (c) the provision of teacher's guidance of the process of understanding in learning. Furthermore, the research explained that understanding will be formed if: (a) learning occurs under conditions that are individually significant, (b) the intense social interaction between teachers and students, (c) one of the result of education is a development of the student's behavior, (d) students face in personally. This oopportunityy when is viewed in depth—using fiduracy theory proposed by Tallcot Parsons (1978)—conclude that social interaction can build a proximate distance that will produce the level of intimacy between social actors.

This such circumstances is opened to mutual understanding each other. The emergence of this understanding because of the emergence of empathy between teachers and students. Individual A interacts with individual B which create a fiduracy field. The closer association between A and B will widen the fiduracy field. At this fiduracy field, dynamics of social interaction will takes place. Furthermore, this fiduracy field contained a process of imitation, suggestion, identification, sympathy. Here, the student's compliance to their teacher is not caused by fear, but due to the professionalism of teachers. This relationship is so strong when teachers are able to demonstrate and guide students to the educational measures that have been programmed. In this case, the teacher became caregivers so that students are able to grow and develop in accordance with human nature of life. Thus social relations is indispensable in the world of education. An eeducation world with a full charge of social interaction will be very positive if there is a balance in the relationship between teachers and students. A balance refers to a reciprocal relationship pattern in the sense that at a certain position, the students collaborate with their teachers. For example, on the implementation of English subjects in schools has shown that students who have high frequency in touch with their teacher, had many opportunities to practice the language learned. This suggests that an increased social interaction with teachers will give a great opportunity to raise fiduracy field. Social interaction processes of education charged will happen with the advent of the socialization process.

This process includes: (a) a ccooperation is given meaning as a joint effort between individuals or groups of people to achieve one or more goals together; (b) an aaccommodation of demonstrating to a situation, 
and refers to a process. An aaccommodation which refers to a state, means the existence of an equilibrium in the interaction between the actors interact with the values and norms of society (Rozikin, 2005).Siagian (2000) found that the teachers and students have the most strategic position in educational activities at the school track. The most difficult thing is to maintain a balance between the teachers' demands to do with the atmosphere of the normative ideal that materialistic, individualistic, and competitive. Underlying factors associated with the professional performance of teachers is related to the job satisfaction of teachers welfare (Surya, 2000). Conditions of teachers according to the results of this study are difficult to understand because the teacher is not in line with the ideals of the reality. In Indonesia, the profile of teacherr as educators is confusing because the position has shifted in the expansion of stratification. Compared to the professionals in other fields, professional teachers are not managed properly, otherwise professional in another field is maintained automatically. Teachers in Indonesia face charges higher capacity but not prepared properly. Analysis about the poor quality of teachers should be based not only on existing educational preparation and a low salary but also sociological variables in general.

Asrin (2006) conclued that: (a) the principal leadership on quality culture include: (1) the strong articulation of the vision and mission as a self-image principal and school organization, dissemination and implementation through short-term plans, term plans length as well as school activities, (2) the values of the principal's leadership is manifested in organizations such as discipline, honesty, courage in innovation, democracy, responsibility, independence, devotion and togetherness, (3) interpretation of the principal values of the school symbol for preserving, maintaining and enhancing a healthy school, (4) the principal creates intrinsic and extrinsic awards to the teachers, administrative staffs and students for their accomplishments, (5) school principals create management school for leadership effectiveness, (6) the school principal builds a social relationships and an emotional accordance with each school's unique form of relationship, (b) the school's quality culture consist of: (1) improving the quality of intra-and extra school services, (2) increasing the quality of school principal, teachers, dan administrative staffs by conducting supervising, coaching, and training, (3) improving the quality of facilities/infrastructure through the development of school laboratory facilities, library, instructional media, and school support facilities such as canteen, cooperative, and others.

\section{The Theory of Perception}

Perception theory can be used as a tool to explain the research on the public perception of the existence of the ISBSHS. In the paradigm of sociology, this theory lies in the paradigm of social behavior. However, because it is a study of the perception therefore it requires a approach of paradigm of individual behavior. Upon entering the study of public perceptions, this study should enter the social definition paradigm, given the perception that views have led to the perception of many individuals who blend constructed as public opinion.

Furthermore, the perception theory was inspired by the individual as a determinant role in the social phenomenon as revealed by Gidden (1991), that all humans are born with the capacity to create a perception that is different from one another in response to an external stimulus that comes from human beings. The differences between the perceptions of each individual becomes a necessity and identified by Gidden as the observation arena among psychologists. This is reasonable, since psychology became a quite fertile contributor to the development of contemporary sociology. In the tradition of psychology, perception regarding to individual responses on stimuli that come from outside. The response may be either verbal or non-verbal. A verbal perception manifested in a lot of perception, opinion or valuation of the phenomenon beyond human self, and a verbal perception is widely expressed in the form of suggestions or ideas as part of a continuation of the response to stimuli. In a non-verbal, a a perception can be poured in a fairly expressive body language i.e. someone who does not like what he saw would respond in a way wince or sigh. In short, one's perception of stimuli can be expressed through verbal sentence as a representation language, attitudes and behavior and as a form of non-verbal perception, or the response of other body language in response to a given person's actions against individuals.

The process of human perception as well as encouraging an attitude or action is done through several processes. This process begins with obtaining the stimulant in the form of information. Due to the limited ability to identify a whole, people tend to make an effort to classify objects or so-called "grouped objects" which is the tendency to regard certain objects together (Miller, 1956). Subsequently, efforts were made to generalize the objects and to measure the relationship among them (Heider, 1946 and 1965).Perception circumstances that formed in that process will be affected by a continuous flow of new information from the environment, in which the sensing process involves peripheral to the surroundings. Subsequently, it creates a holistic form and in high constancy, which can also be applied in other places and objects (Osgood 1953). Meanwhile, according to Merleau-Ponty (1945), the

perception is the background from which radiates all the activities and always presupposed by such activities. He said the perception is not just a supposition, but also the path to the truth that is created from empiricism and rationalism or reality.In the next process, perceiving is also considered as a control to the actions and behavior process, one of which is a process of adjustment. This process begins with a group of organisms 
to adapt a certain behavior which is the behavior of a group of organisms adjustment to certain conditions, which is then followed by other organisms whenever they know and understand the benefits-learning process (Suparlan, 1986). Next, they choose or do a certain set of behaviors to adapt to the environment, that it contains the values, the level of social organization and certain technology used in adapting to the changes that occur that is referred to as an adaptive strategy (Bennett, 1976). Therefore one of the goals of this study is ton trace the stakeholders including the public perception of the existence of the ISBSHS. It absolutely requires a discussion of perception theory as an explanatory tool. A crusial matter to be studied in this research is to know how the perception of the informants and how a shift in perception of the existence of the ISBSHS located in remote rural area Pacet, East Java Province, Indonesia.

\section{The ISBSHS's Concepts}

The ISBSHS's aim is to graduate the students who have international academic ability and belief in God-Allah SWT. Therefore, the ISBSHS is a school that meets Indonesian National Education Standards and also the education standards applied by the member country of Organization for Economic Cooperation and Development (OECD) and other developed countries. Hence, its graduates have a competitive edge in the international forum. In principle, the school must be able to guarantee the quality of education to international standards that are higher than the Indonesian National Education Standards.

\section{Research Methodology}

The study's site was the International Standardized Boarding High School of Amanatul Ummah (the ISBSHS) located in Pacet, East Java Province, Indonesia. Rationale for establishing a research site is based on considerations as follows: (1) The ISBSHS is located in a remote area Pacet, East Java Province, Indonesia. Pacet is a mountainous area that has a high socio-economic development of the region. It is due to a tourism region that has high levels of social development, economy and culture.Thus the area is more plural and dynamic. The area is also having many public schools and madrasah from elementary to upper level. So the level of competition among the existing schools to provide the best services for the community is relatively high. (2) A local community is the people who related to the existence of the ISBSHS, not the local people in the geographical sense. The research is conducted by visiting and opening up communication or face-to-face with the person who selected as informant. Interviews were conducted intensively or in depth to the key informants and other resources to obtain information about the views or opinions and their responses regarding the ISBSHS. Researcher interviewed the selected parents of students, people outside the selected parents, selected students, most of the teachers, principal and chairman of the foundation.Relevant documents, such as curriculum, syllabus, the rules as well as various other documentation that supports this research. We employed the Engineering Analysis Taxonomy (Taxonomic Analysis). The reason is that the researcher wanted an outcome of the analysis focused on specific domains which are then described and elaborated in sub domainspecific sub domain. Thus, the details of the domains can describe the 'up' construction of the public perception of the ISBSHS.Thus, the selection of the domain is the focus of analysis, it is determined by how big a role these domains can explain more about the conducted research. Therefore, regard to a research on Stakeholders' perceptions domain of the ISBSHS include: experience, mind, confidence, comprehension and public opinion.

\section{Results}

To gather information from stakeholders, the information was collected through interviews with relevant parties particularly the parents, education experts, the board of the ISBSHS's teachers, administrative staffs, director of the ISBSHS, community leaders, and communities who have direct or indirect access to the existence of the ISBSHS. Table I shows the resume of the perception of stake-holders toward the presence of the ISBSHS.

The list of questions related to the experiences, minds, understandings, attitudes and the belief of the ISBSHS's presence.

Table 1 The stake-holders' perception classification toward the presence of the ISBSHS.

\begin{tabular}{|c|c|c|c|}
\hline Domain & Sub domain & Findings & Underlying or Emerging Concepts \\
\hline $\begin{array}{l}\text { Perception of } \\
\text { Stakesholders }\end{array}$ & Experience & $\begin{array}{l}\text { 1. A good experience during study at } \\
\text { the Junior Boarding School of } \\
\text { Amanatul Ummah gives a } \\
\text { confidence to the students who } \\
\text { continue to study at the ISBSHS } \\
\text { 2. Initially the students underestimated } \\
\text { the ISBSHS, but after the they went } \\
\text { through the process of learning, } \\
\text { most students were felt that the }\end{array}$ & $\begin{array}{l}\text { The findings showed the Giddens concept } \\
\text { of perception, phenomenology, and } \\
\text { symbolic interactionism, that the ISBSHS } \\
\text { was initially underestimated. However, } \\
\text { after going through the process, it gave a } \\
\text { good experience and impression to } \\
\text { stakeholdders. It means that there has been } \\
\text { a shifting perceptions of stakeholders } \\
\text { toward positive one. }\end{array}$ \\
\hline
\end{tabular}




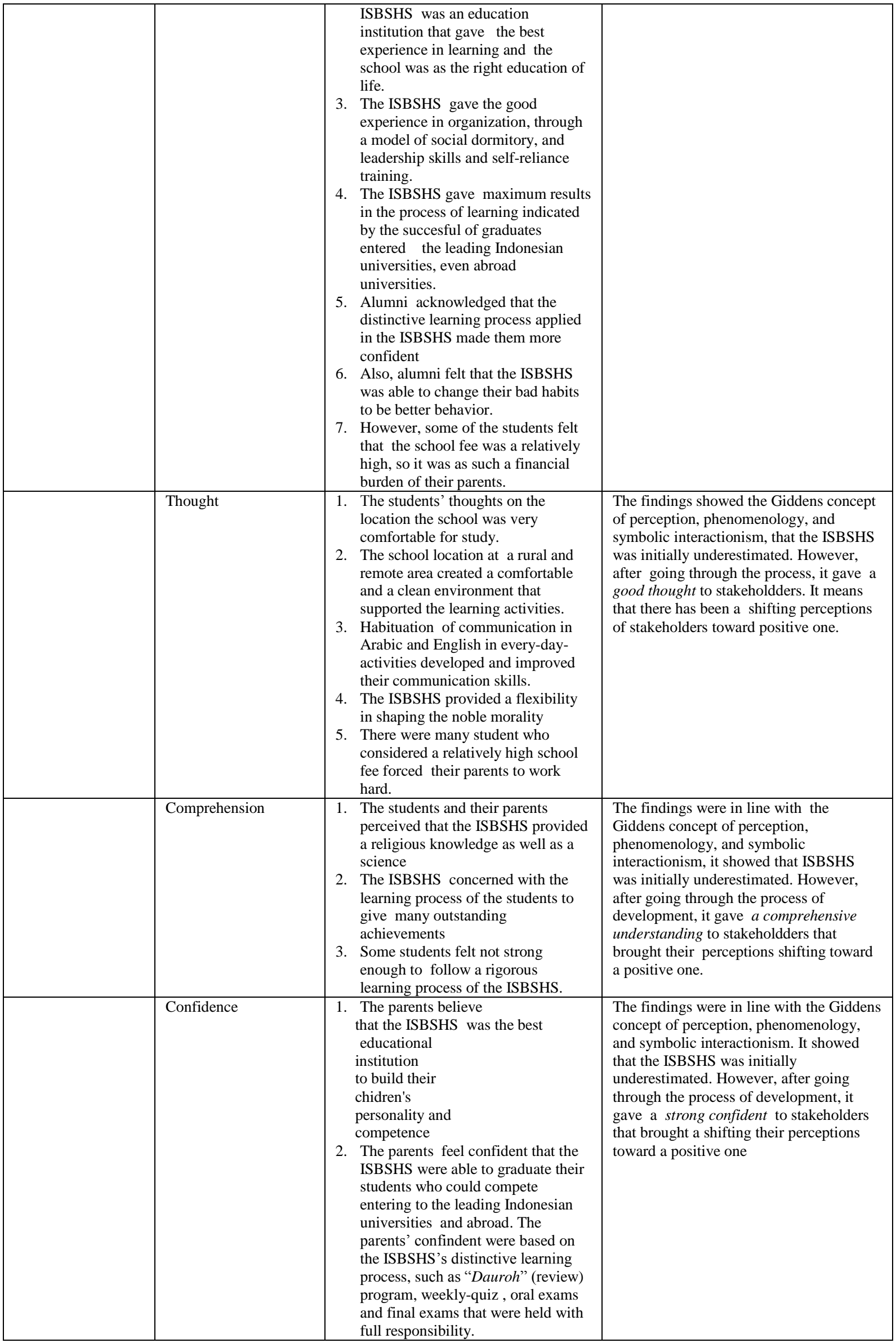




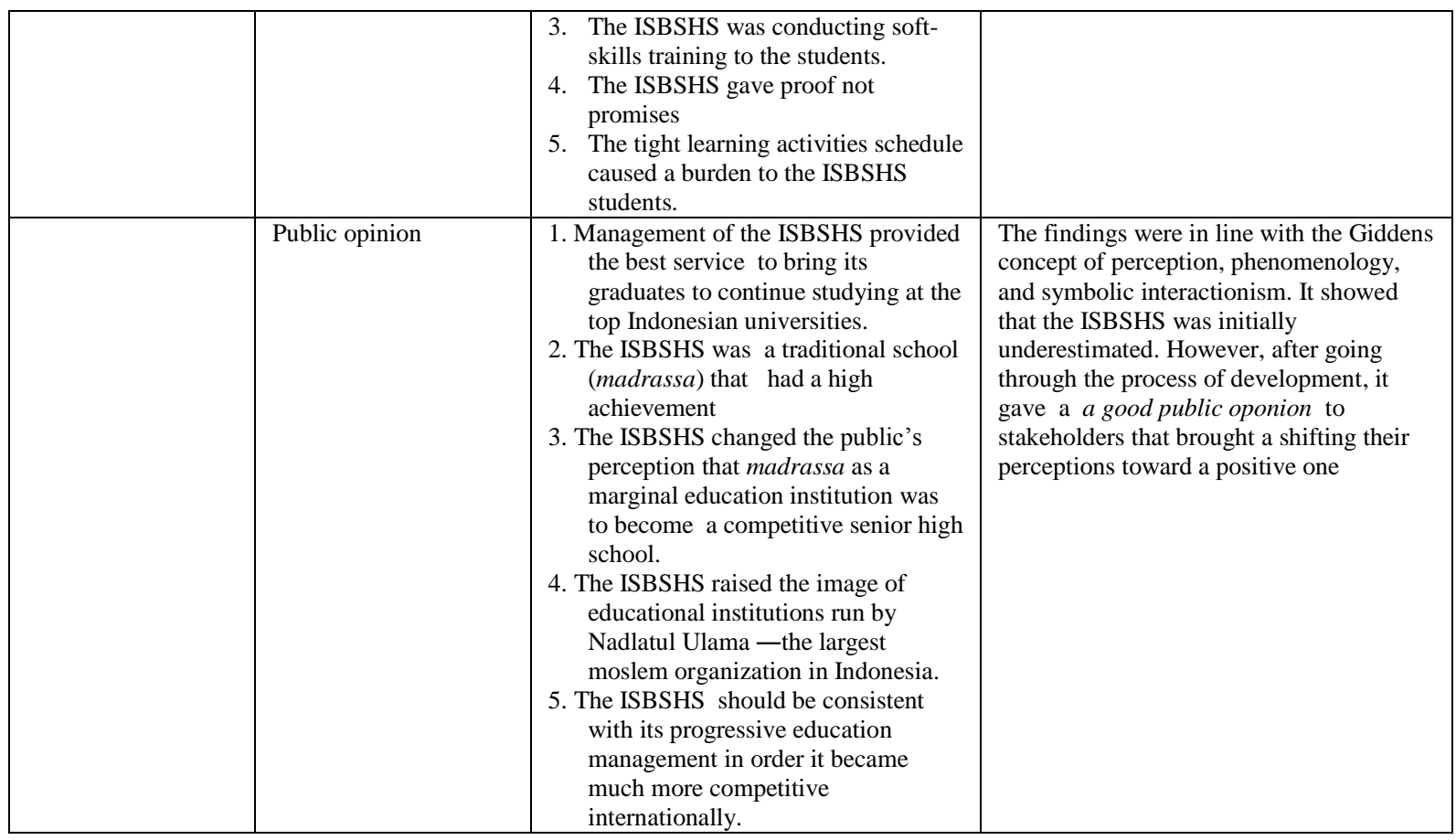

Source: Adapted from observations and interviews

\section{Analysis And Discussion}

Based on the informations that were collected, there was a positive perception toward education institutions which were responsible to the students by applying a distinctive education program. It is also found that the community, parents, education stakeholders and experts, including the management of the ISBSHS, initially had a negative perception toward the ISBSHS. It was because of unsufficient of facilities and infrastructure of the ISBSHS. However, this situation suggested the management of the ISBSHS to prioritize mentoring services to all students. Meanwhile, the ISBSHS continued to develop its fasilities and infrastructures to provide excellent education services. Improving facilities and infrastructures of the school was one of the factors that made a perception shifting of both the internal and external parties toward the positive one. The of the management determination of building the school created an understanding, a belief, and opinions that simultaneously brought a good impression and recognition which strengthened the position and role of the ISBSHS from the local level to the national level. Local people seemed more comfortable with the presence of the ISBSHS following the school's involvement in deloping public facilities needed by local community. More over, the Amanatul Ummah Foundation has undertaken corporate social responsibility (CSR) by giving scholarship to children who lived surrounding the ISBSHS area. The CSR reinforced the people's perception to be positive. The shifting of the public perception was acknowledged by community leaders, such as: Mr. Warji, Mr. Tawi and Mr Bambang. This community leader's perception shifting was an interesting finding that showed the ISBSHS became an accepted education institution, even it became the icon of all Pacet community because of its outstanding performance.

Another finding was the experience of the first alumni of the ISBSHS of 2006/2007 such as Adi Wiratama, Syaikhu Rofiq, Ahmad Afiq, Mulyandi and others. They were so proud of becoming part of the ISBSHS as the best boarding school in Indonesia, eventhough initially they have had a bad impression. However, there were some complaints about the facilities. But, these complaints motivated the management to work hard in term of developing an excellent formal and religious educational services and softskills training as well. Eventually, most of alumni made a statement: "the ISBSHS is the greatest school they ever felt".Moreover, a positive perception toward the ISBSHS came from educational experts who initially were pessimistic . Professor Agus of the Institute Technology of November $10^{\text {th }}$, the top-five Indonesian university and Professor Hussein of the Islamic State Institute, Surabaya, Indonesia who contributed the success of the ISBSHS. They also involved in the development of the school.It is not surprising, the ISBSHS was pointed by the Regional Office of the Ministry of Religious Affairs of East Java Province as a good governance educational institution. For the last 5 years, there are many school delegations coming from other provincies to undertake comparasion study.

Mr. Didik-originally Indonesian - who had lived in Australia for 4 years also stated that the ISBSHS deserved a predicate as the real international standardized senior high school. Other findings, in fact, when attending farewell party held by the ISBSHS, Taylor Djeffrey Smith, the member of the American Indonesian 
Exchange Foundation (AMINEF), who had lived and taught in the ISBSHS expressed his good impression toward the ISBSHS's performance. In addition, it has already established an intensive communication between the students and teachers of the ISBSHS with the AMINEF members, including Mathew David Smith, the first staff of AMINEF who taught in the ISBSHS, although it was done by internet media. All of this was a proof of the existence of the ISBSHS truly memorable for anyone who ever lived in that school.

The presence of Ro'isul Bitsa-teacher or messenger —of Al Azhar, Egypt at the ISBSHS was viewed as a positive indicator of the positive perception of overseas partners, especially on the implementation of the curriculum of mu'adalah-Islamic teaching. It was rarely that an emissary leader based in the Egyptian Embassy in Jakarta, the capital city of Indonesia, had time for visiting to an educational institution. But it was no the case in the ISBSHS. Moreover, the leader considered the school as an quality-based boarding school.

As we know that globalization will increase the level of competition in the market of any commodity and service, including service of education. To anticipate the globalization, the ISBSHS has applied a continuous improvement management in order to keep its competitive advantage. One element of the continous improvement management is "dauroh" program that is reviewing each subject of all topic to make sure that the students have higher competences. In the context of the field perspective, Mead $(1934,1936)$ has observed of how the mind of each individual is creative causing a social behavior. The combination of subjective-self and the social-self can create a collective action that explains the perception or personal mind into the attitudes and actions of the informants. Meanwhile, the perception which is influenced by the background of the informant is a reality that can be approached with the Blummer's symbolic interactionism explanation. Negotiations implied by Blummer (1969) is reasonable, because an agreement among members of the community to perform certain actions is indeed the case of the desired common perception of the symbol in the 'joint action'. Perceptions and motivations that influenced by the background range of informants representing variations of these perceptions and attitudes of the informants. In these terms, Blummer emphasized on the social organization of different actions from different actors. Thus, Blummer's study is more interactionist than Mead's which only stop at explanations of creative actors who create social behavior. Blummer come more comprehensively, by displaying an explanation for the possible actions that vary depending on each individual's ability to interpret the symbols that emerge in their social environment. Perceptions and motivations that influenced by the informant's background which is determined by individual's interpretation of local communities toward the presence of the ISBSHS.

Goffman (1982), argued that the distance extends between social expectations with the role to be played by a subjective self is actually an explanation of the action of other phenomena in the field. A role to be played by the individual becomes so multifaceted. This is because 'self' regards a structure as something that does not have to be obeyed, but occasionally may be resisted. Furthermore, Ritzer (1996) unified the existing paradigm in sociology by developing and reflecting the existing paradigm that bring us to the important point of the integrated paradigm lies in the multilevel position. That is, social reality is seen as a huge variety of social phenomena that continuously involved in the interaction and change. Some Ritzer's view of integrated paradigm are as follows. First, microscopic continuum, that is the thinking about social reality as coming from a broad scale to a smaller scale is relatively easy to recognize. Secondly, the objective-subjective dimension of social analysis. From the tip of the social micro-macro will be found objective-subjective component. Objective component is related to the social reality and the material events. In this paper, Ritzer' study is employed then appropritate to analyze the whole interaction between the internal community of the ISBSHS with external community, such as parents, stakeholders, and the surrounding communities including education experts. Motivation, goals and objectives of the informant then certainly were very related to the her/his perception toward the presence of the ISBSHS. Therefore, the basic core of the diverse phenomenological explanation should at least be referred to one by one in order to obtain an adequate explanation. Patterns of interaction which is a synergy of action and reaction of the actors within the ISBSHS and the community and stakeholders, must take place as a result of interpreting the mutual understanding of each others through symbols sent by each actor. In this case, the actors were the internal community of the ISBSHS including teachers and students, parents, and local communities, community leaders, as well as the education experts. All of these actors must have a certain capacity to judge, to respond, to motivate, to believe, to hope, and to understand following on every action.

Therefore, the phenomenology helps in seeing the phenomenon that takes place in the area of research. The phenomenologist always sees what is behind the facts. In the context of this study, it provides an explanation of ongoing interaction between all the involved components and actors. The presence of many subsequent interpretations have led to the understanding and interpretation of reality that has been ongoing relationship patterns. 


\section{Conclusion}

Based on the description in the previous section, then there are some of the major conclusion, namely: perception of parents, stakeholders, students, alumni, education experts and community leaders initially was not a positive toward the presence of the ISBSHS due its limited available infrastructures. But after a few years, in line with the effort to achieve various accomplishments and successes, there was a shift in perception toward believes and recognizes, in fact even giving support to the ISBSHS growing better. Thus, increasing the perception of stakeholders was able to improve the confidence in the quality of learning systems in order to achieve the educational goals of academic, moral and religious.The perception of stakeholders has grown increasingly better that can improve the confidence of stake-holders on the quality of learning systems in order to achieve the educational goals of academic, moral and religious".Perceptions, opinions, beliefs, and attitude of parents, students, communities, community leaders and education observers or experts initially doubted the existence of the ISBSHS. But over time, in line with the many evidences of the ISBSHS's successes an outstanding achievements, perception has been shifting 'the real international standardized boarding senior high school. As suggested by Giddens $(1981,1992)$ that each person will tend to give a response to what has been seen and been felt. The ISBSHS does not escape from the reaction to the positive response.

Practical implications that can be concluded from the findings is that the perception of parents, students, alumni of the ISBSHS, education experts and community leaders about the school was initially not giving a positive response due to the limited available facilities and infrastructure at the beginning of the establishment. However, after a few years, in line with many school's achievements and successes, there is a shift in perception toward the better one. These realities were seldom experienced by similar institutions.

Therefore, researcher give the suggestion as follows. The need to improve the quality of administration in line with the increasing number of guests who want to know the blueprint of education applied in the ISBSHS. The need to provide adequate facilities and infrastructure, since the inception of the ISBSHS, were only one building with 2 class-rooms. Although it is currently being built a physical development, but the provision and improvement of school facilities must be improved especially sports facilities and a mosque with a larger capacity. The need for the dissemination of success of the ISBSHS-as a religious-based boarding senior high school under administration of the Ministry of Religious Affairs of the Republic of Indonesia- as an underperformanced education institution.

\section{References}

[1] Ahmadi, Abu. (1991). Sociology of Education. Jakarta: Rineka Cipta

[2] Ambert, A-M, et.al. (1995). "Understanding and Evaluating Qualitative Research", Journal of Marriage and the Family, Vol. 57 No. 4, pp 879-893

[3] Arifin, Imron. (1998). The Principal Leadership in Managing Madrassah and Elementary School Achievement. Malang: PostGraduate Program of State University of Malang (NotPublished).

[4] Asrin. (2006). Principal Leadership in Quality Culture School. Malang: Dissertation of Post- Graduate Program, State University of Malang (Not Published).

[5] Bennett, John W., (1976). The Ecological Transition: Cultural Anthropology and Human Adaptation. New York: Pergamon Press Inc

[6] Blumer, Herbert. (1969). Symbolic Interactionism, Perspectives and Method. Berkeley: California University Press

[7] Giddens, Anthony. (1981). A Contemporary Critique of Historical Materialism, vol.1.Barkley and Los Angeles: University of California Press

[8] Giddens, Antony. (1992). The Transformation of Intimacy, Sexuality, Love and Society in the Late Modern Age. Cambridge: Polity

[9] Goffman, E. (1961). Encounters: Two Studies in the Sociology of Interaction. USA: The Bobbs-Merrill Company.

[10] Goffman, E. (1982). Interaction Ritual: Essays on Face-to-Face Behaviour. New York: Pantheon.

[11] Goffman, E. (1986). Frame Analysis: An Essay on the Organization of Experience, Boston: Northeastern University Press

[12] Goffman, E. (1990). The Presentation of Self in Everyday Life, London: Penguin.

[13] Heider, F.(1946). Attitudes and Cognitive Orientation. Journal of Psychology, 21, 107-112.

[14] Heider, F. (1958). The Psychology of Interpersonal Relations.New York: Wiley

[15] Merleau-Ponty, M. (1958). Phenomenology of Perception.Translated by Colin Smith.New York: Rout Ledge-Classics

[16] Mead, George. (1934). Mind, Self and Society.Chicago: University of Chicago Press.

[17] Mead, George. (1936). Movement of Thought in Nineteenth Century.Chicago: University of Chicago Press

[18] Miller, G. (1956). "The Magical Number Seven Plus or Minus Two: Some Limits on Our Capacityfor Processing Information." Psychological Review 63:81-97. Parsons,

[19] Talcott. (1978). Sociology. New York: Alfred A Knof.

[20] Osgood, Charles, George, Succi, Tannenbaum, Percy, (1957). The Measurement of Meaning. University of Illinois Press,Urbana

[21] Saha, Lawrence. (2008).Sociology of Education" $21^{\text {st }}$ Century Education.Thousand Oaks, CA:Sage Publications

[22] Sherraden, M.S. \& Barrea, R.E. (1995). Qualitative Research With an Understudied Population: In-depth interviews with women of Mexican descent. Hispanic Journal of Behavioral Science, 17, 452-470

[23] Siagian, S.P. (1995). Human Resources Management.Jakarta: Bumi Aksara

[24] Sujarwo. (2000). Sociology and Culture. Yogyakarta: Pustaka Belajar

[25] Suparlan, Parsudi. (1986). Culture and Development. Jakarta: Media IKA

[26] Surya, Mohammad. (2000). "Aspiration of Professional Skill Development and Teacher's Welfare. Education and Culture Journal. No. 021

[27] Ritzer, George. (1992). Contemporary Sociological Theory. New York: McGarw-Hill, Inc.

[28] Ritzer, George. (1996). Modern Sociological Theory.New York: The McGraw-Hill Companies 